\title{
Axial Compressor Stall and Surge Prediction by Measurements
}

\author{
H. HÖNEN* \\ Institut für Strahlantriebe und Turboarbeitsmaschinen, RWTH Aachen (Aachen University of Technology), \\ 52062 Aachen, Germany
}

(Received 3 April 1997; In final form 10 July 1997)

\begin{abstract}
The paper deals with experimental investigations and analyses of unsteady pressure distributions in different axial compressors. Based on measurements in a single stage research compressor the influence of increasing aerodynamic load onto the pressure and velocity fluctuations is demonstrated. Detailed measurements in a 14-stage and a 17-stage gas turbine compressor are reported. For both compressors parameters could be found which are clearly influenced by the aerodynamic load.

For the 14-stage compressor the principles for the monitoring of aerodynamic load and stall are reported. Results derived from a monitoring system for multi stage compressors based on these principles are demonstrated. For the 17-stage compressor the data enhancement of the measuring signals is shown. The parameters derived from these results provide a good base for the development of another prediction method for the compressor stability limit. In order design an on-line system the classification of the operating and load conditions is provided by a neural net. The training results of the net show a good agreement with different experiments.
\end{abstract}

Keywords: Stall and surge monitoring, Unsteady pressure measurements, Compressor load analysis, Load parameters, Neural nets

\section{INTRODUCTION}

The requirement of high economy of turbomachines causes higher efficiencies and power densities with increasing profile and assembly loads. On the other hand the loads are limited by the requirement of operational safety of the machine. Therefore, the main aim is the guaranty of the availability on a high level. This aim only can be reached by an increasing observation and monitoring of the operational conditions inside the machine.

Various efforts have been made to find measuring and analysis methods for the detection of the stability limit of compressors (Ludwig and Nenni, 1979; Paduano et al., 1991; Wang et al., 1993). For save compressor operation it is necessary to know

\footnotetext{
* Fax: 0241-8888-229.
} 
the distance of the momentary operation point from this limit. Therefore, the detection of the occurrence of stall is not the only aim of all these struggles. Moreover, an indicator for the approximation to the stability limit has to be found. Several investigations are looking for so called stall precursors which can be harmonic waves superposed to the flow or other fluctuations which induce the beginning of stall (Inoue et al., 1990; Garnier et al., 1990).

Due to the progress in computer development it is more and more possible to pick up and handle a high number of measuring data on-line. Even unsteady effects can be observed in real time. Thus, the on-line calculation and observation of characteristic values becomes realistic. The combination of a suitable definition of detection and observation parameters based on measuring results together with the corresponding analysis algorithms enables the operator to run a compressor close to the stability limit at high efficiencies.

\section{EXPERIMENTAL INVESTIGATIONS}

Measurements in three different axial compressors show the influence of the aerodynamic load onto the patterns of unsteady flow distributions. Experimental investigations of the unsteady three dimensional flow inside a single stage research compressor provided a basis for the understanding of the unsteady effects in separation zones (Gallus and Hönen, 1986). Furthermore, these measuring results visualized the influence of separated flow regions onto the signal form and behavior of wall mounted dynamic sensors as well as probes.

The aerodynamic load of the compressor was increased up to the stability limit. Measurements with hot wire probes in the axial gap between rotor and stator demonstrated the changes of the unsteady flow patterns downstream the rotor. Depending on the higher load the profile boundary layers become thicker which can be detected in wider blade wakes. In addition the stochastic fluctuations are elevated and a higher turbulence level is detected. Figure 1 demonstrates these effects for two different operating points of the stage. The radial turbulence distributions for the axial gaps between the bladings visualize the influence of the aerodynamic load onto the flow in the entire stage.

Due to the increasing aerodynamic load a corner stall region with fluctuating boundaries occurs in the stator. With higher loads this seperation zone grows in to the blade passage. Glue on hot film sensors on the stator vanes provided information about the behavior of the unsteady flow. Thus, the extend of the corner stall region inside the stator could be observed. One major result of these investigations was the experience that only sensors outside of the separation region were able to measure periodic fluctuations due to the rotor/stator interaction. Measuring sensors positioned inside this separation zone can only detect high turbulent fluctuations. All periodic information damped down and does not reach the sensors.

Measurements in a 14-stage gas turbine compressor provided detailed information about the unsteady flow behavior in a multi stage compressor influenced by different compressor loads. For a long term investigation the stages 11 and 13 were equipped with wall mounted piezo-electric pressure sensors in the axial gaps between rotor and stator. The measurements were carried out for a period of about four months during industrial operation under full load conditions of the gas turbine. During these measurements a failure in the gas turbine control system occurred and the operating point of the compressor drifted very slowly towards the stability limit. Finally the surge control of the gas turbine provoked a shut down.

During this time period the pressure sensors registered the same effect as demonstrated in the single stage compressor. At a certain load level in the 13th stage the periodic information disappeared. This indicates that here a separation region occurred which covered the measuring sensor. In order to be able to handle the great number of data from the long term investigation a data reduction by FFT analysis was carried out (Fig. 2). About half an hour before the automatic shut down the 


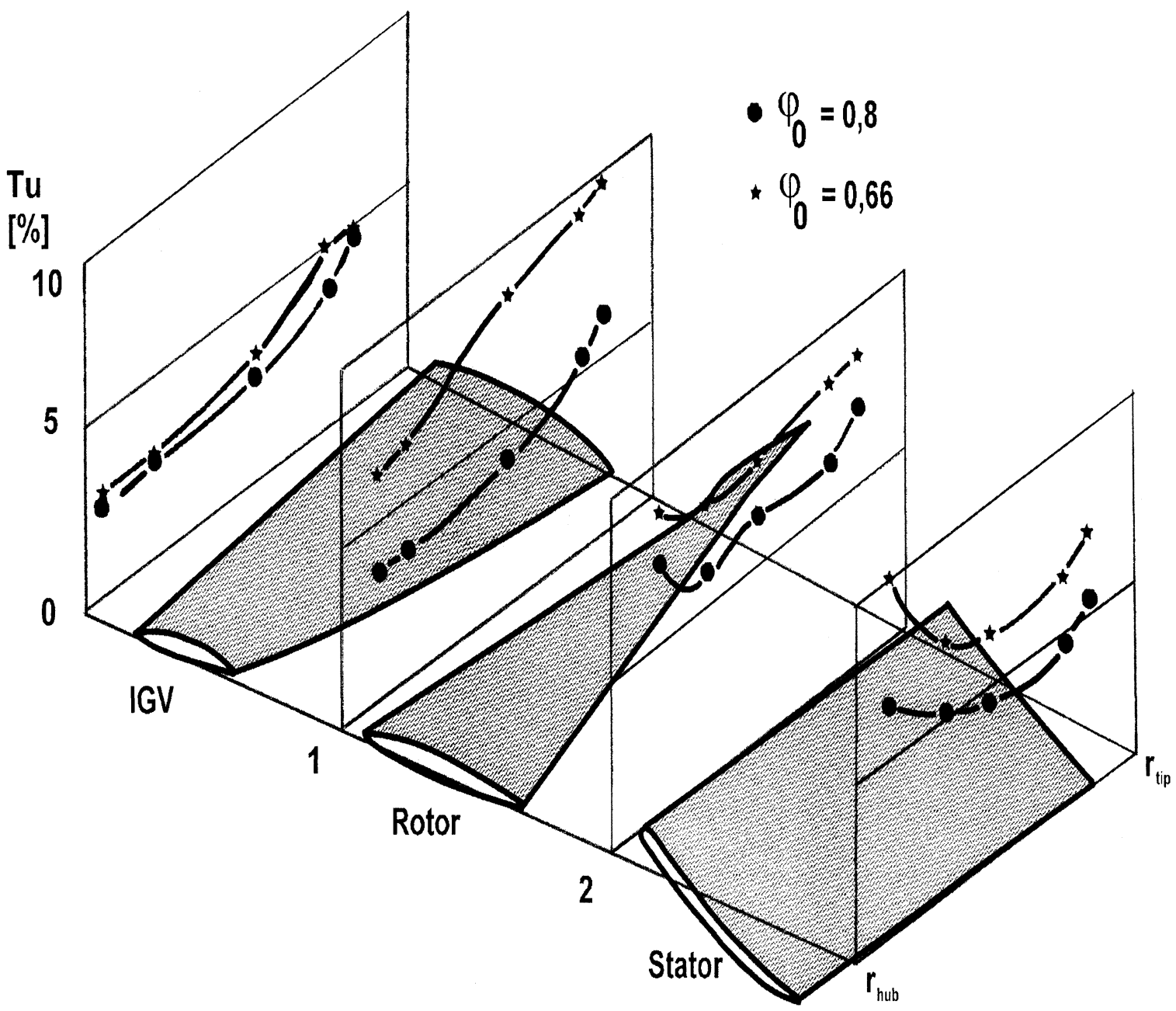

FIGURE 1 Turbulence distribution in the axial gaps of a single stage research center.

frequency spectra of the 13th stage only showed high noise levels, whereas in the 11th stage the characteristic peak was increased caused by growing blade wakes due to the higher aerodynamic load (Hönen and Gallus, 1995).

The growing profile boundary layers in the rotor are centrifugated to the casing where side wall boundary layer thickness itself is also increased. This causes an accumulation of low energy material behind the rotor. The high back pressure at the compressor outlet disables the exit flow so that a casing stall occurs. This separated region covers the wall mounted pressure sensor and damps down the periodic information coming to the measuring position.

Another investigation was carried out in an industrial gas turbine. On a test field detailed measurements were taken in the 17-stage axial compressor. The first two stages were equipped with five wall mounted dynamic pressure sensors in the casing over the rotors at several axial positions. In five test runs at part load with different operating conditions (Table I) the rotor speed of the machine was reduced until the stability limit of the compressor 

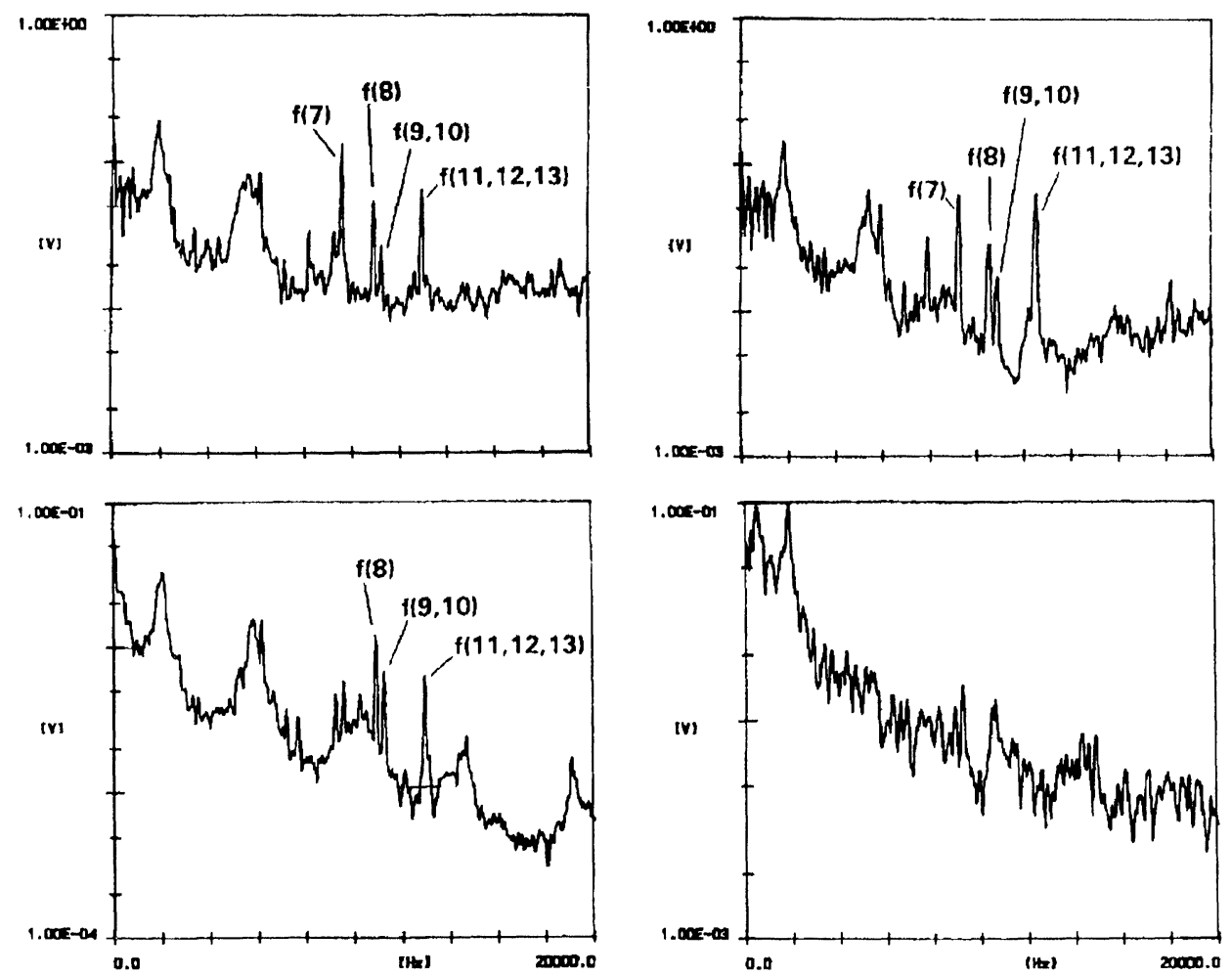

11 th stage

13th stage

FIGURE 2 Comparison of the frequency patterns in the 11th and 13th stage for two operating points (left side: norma operation, right side: stall operation).

TABLE I Comparison of the operation parameters for different test runs

\begin{tabular}{lcccc}
\hline Test run & VSV position & Bleed door \#1 & Bleed door \#2 & Bleed door \#3 \\
\hline 1 & $20^{\circ}$ & Closed & Closed & Closed \\
2 & $0^{\circ}$ & Open & Closed & Closed \\
3 & $0^{\circ}$ & Closed & Closed & Closed \\
4 & $20^{\circ}$ & Closed & Closed & Closed \\
5 & $20^{\circ}$ & Open & Open & Closed \\
\hline
\end{tabular}

was reached. The pressure signals were recorded in real time to a magnetic tape recorder and analyzed after the experiments.

As an example the time averaged signals of the first test run are shown in Fig. 3 for the first measuring position in stage 1 . The patterns of the first four pressure transducers show the wall pressure distribution above the passing rotor channels for the different sensor positions. From the suction side to the pressure side of the channels the static pressure is elevated up to a maximum. Just after the passing of the rotor blade a sharp decrease is observed due to the lower pressure at the suction side of the profile. The last measuring position is located in the axial gap between rotor and stator. Here the flow is influenced by the blade wakes downstream of the rotor.

It becomes obvious that the signal patterns strongly depend on the measuring position. In the front part of the blading the signal forms are 

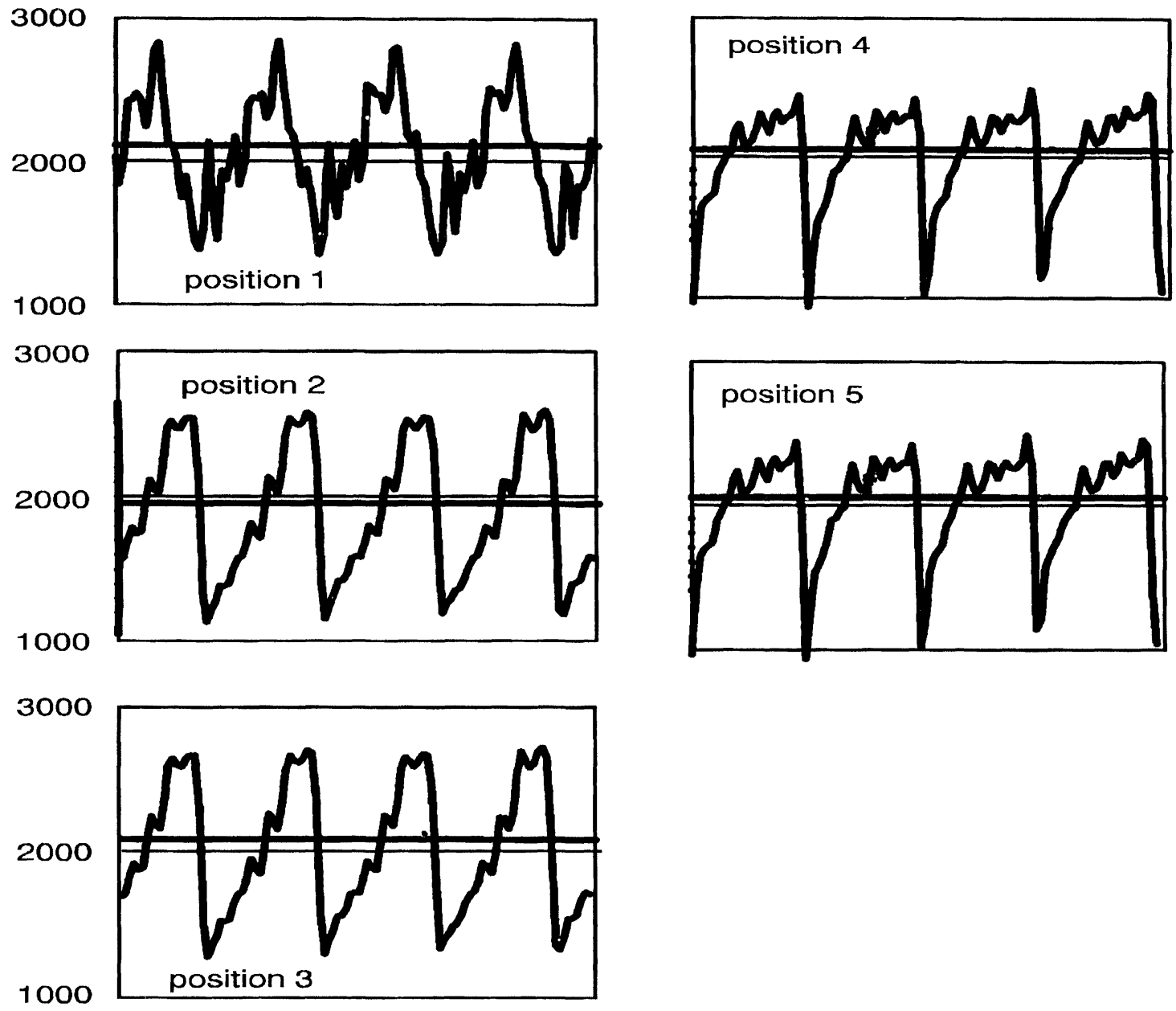

FIGURE 3 Time average pressure signals at the measuring positions over rotor 1 .

influenced by many different flow effects. In the last third, especially at measuring position 4 a low and a high pressure region inside the blade channel can be observed. Here the pressure differences between blade suction side and pressure side become very high.

The frequency spectra calculated from the pressure signals at sensor positions 4 over the rotors 1 and 2 are shown in Fig. 4. From top to bottom the diagrams demonstrate the behavior with increasing aerodynamic load. A clear dependence from the compressor load can be detected. The first pattern shows the normal operation conditions and the last one shows the conditions about 50 revolutions before the beginning of surge. For the rotor blade harmonics especially at the measuring positions in the last third of the first rotor decreasing amplitudes can be detected. This behavior is quite different in comparison with the results from the 14-stage compressor investigated under full load conditions due to the different flow effects observed inside and outside the blade channels.

At full speed the stability limit of a compressor is defined by the stability limit of the end stages, whereas in this case the stages in the front part of 


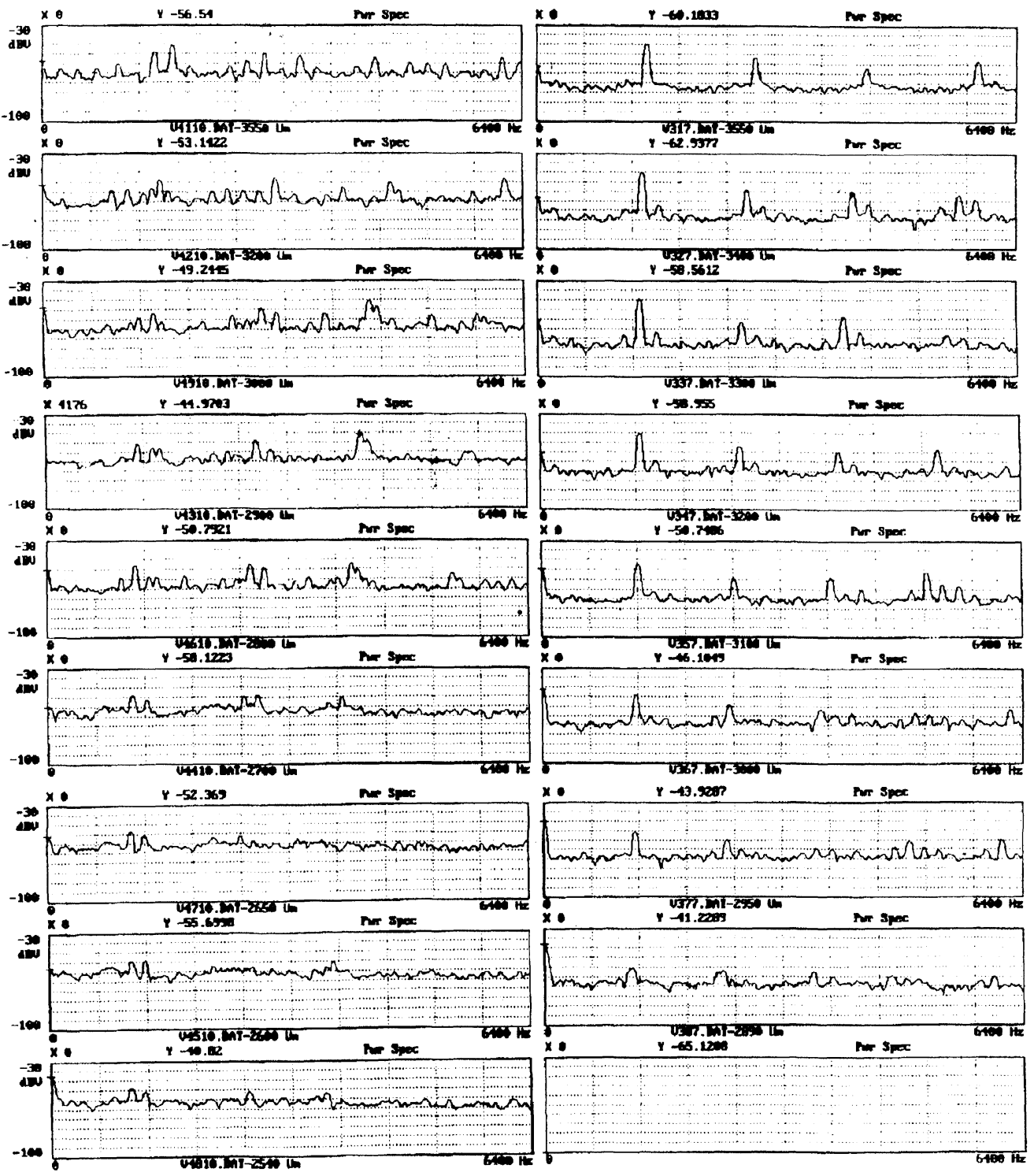

FIGURE 4 Frequency spectra over rotors 1 and 2 for different operating conditions.

the compressor are responsible for the stability limit. In the axial gap the pressure signals show the periodic fluctuations due to the blade wakes upstream the rotor. At the casing over the rotor the periodic information is caused by the passing of the blades and the pressure difference between profile pressure and suction side.
The increasing pressure ratio of the compressor influences all stages even the front stages. Due to the higher pressure inside the bladings the pressure differences between profile pressure and suction side become higher. Furthermore, the tip leakage flow is amplified which causes higher random fluctuations and losses in this region. 


\section{PARAMETER DEFINITION AND ANALYSIS}

In order to enable the results and observations shown above for a computerized analysis suitable parameters have to be defined. These parameters must contain the main information from the measuring results and transform it into a set of values which can be analyzed by a computer. The measurement of unsteady flow signals provide an enormous number of data which must be reduced for an analysis.

The form of all real time signals shows clearly different patterns with changing aerodynamic load. It becomes obvious that the shape of the rotor wakes as well as the distribution of the low and high pressure region over the rotor blades changes. In addition the random fluctuations become more and more intensive. The behavior of the stochastic fluctuations is characterized by the calculation of the RMS values of the signals and the turbulence levels. These parameters could be found as usable indicators for the increase of aerodynamic load. However, the transformation of the signal shape information into a computer readable form is more difficult. The problem is the definition of parameters which make the signal pattern as well as its variation visible. One possibility is the definition of a normalized value for the amplitude and the duration of the fluctuation.

$$
w_{\text {fluct }}=\frac{t_{\text {fluct }}}{T_{\mathrm{p}}}, \quad h_{\text {fluct }}=\frac{\bar{A}-A_{\text {fluct }}}{\bar{A}} \text {, }
$$

with $t_{\text {fluct }}$ - passing time of the high (low) pressure region; $T_{\mathrm{p}}$ - rotor blade passing time.

For measurements in the axial gap these parameters could be calculated with the wake data. For the investigations inside the blade channels the different pressure regions (see Fig. 3) have to be analyzed.

Another method of data reduction is the FFT analysis. The frequency spectra of the measuring signals demonstrated the influence of the aerodynamic load onto the periodic fluctuations. The definition of a suitable parameter for a computerized analysis must for example provide information about the extend of the harmonics of rotor blade frequency out of the normal noise level. Two possible definitions are shown below:

$$
\begin{aligned}
& p_{\text {val }}=\frac{A(f)-\bar{A}}{\bar{A}}, \\
& p_{\text {val }}=\frac{A(f)-\overline{\sqrt{A^{2}}}}{\overline{\sqrt{A^{2}}}},
\end{aligned}
$$

where: $p_{\text {val }}$ - calculated parameter; $A(f)$ amplitude of the frequencey peak at the observed frequency; $A$ - mean value of the frequency spectrum; $A^{2}-$ RMS value of the frequency spectrum.

In both equations the differences are normalized in order to avoid the influence of different noise levels due to changing ambient conditions onto the parameters. Furthermore, this definition allows a transfer of the parameters to different compressors or to use different measuring techniques for the observation without changing the algorithms.

The major aim of all parameter definitions is to visualize the influence of the observed operating parameter of the compressor, in this case the compressor load. Of course, these parameters are also influenced by other quantities so that the unequivocalness of the declaration could be limited. Therefore, a combination of different parameters is necessary to stabilize the monitoring result.

The measuring results in the 14-stage compressor were the basis for the development of an on-line monitoring system. At full load conditions a monitoring parameter for the stages 11 to 13 was defined corresponding to Eq. (2). With increasing load this parameter is elevated until casing stall occurs and the amplitudes drop down. This effect at first is observed in the 13th stage and with a certain time delay also in the 12 th and 11 th stage. In order to provide a detailed monitoring result for the compressor load with these values a new parameter (SL) for the compressor stability is calculated as an addition of all stage parameters each multiplied 
with a weighing coefficient (a) (Hönen and Gallus, 1995):

$$
\begin{aligned}
\mathrm{SL}= & a_{\mathrm{stage13}} p_{\mathrm{val}_{\mathrm{stage} 13}}+a_{\mathrm{stage12}} p_{\mathrm{val}_{\mathrm{stage} 12}} \\
& +a_{\text {stage11 }} p_{\mathrm{val}_{\mathrm{stage1} 1}} .
\end{aligned}
$$

This monitoring parameter is a good indicator for the stability behavior of the compressor and shows a good agreement with the operating conditions. Figure 5 demonstrates the influence of different compressor load due to changing positions of the variable stator vanes (VSV) onto this so called stall level. High values of VSV postition are equal with low aerodynamic load and vice versa.

The analysis of the measurements at part load in the 17-stage compressor is based on the information of only one stage. In order to provide an algorithm which can be applied to different operating conditions it is necessary to look for parameters which show always the same behavior during the approximation to the stability limit. For the first rotor several parameters could be defined which visualize this trend and can be used as indicators. In a first step from the FFT-spectra values for the harmonics of the characteristic frequencies were calculated using Eq. (3). For the further data treatment and comparison these values must be on the same magnitude level. Therefore, all parameters are normalized with the value at normal operating conditions of the compressor. Figure 6

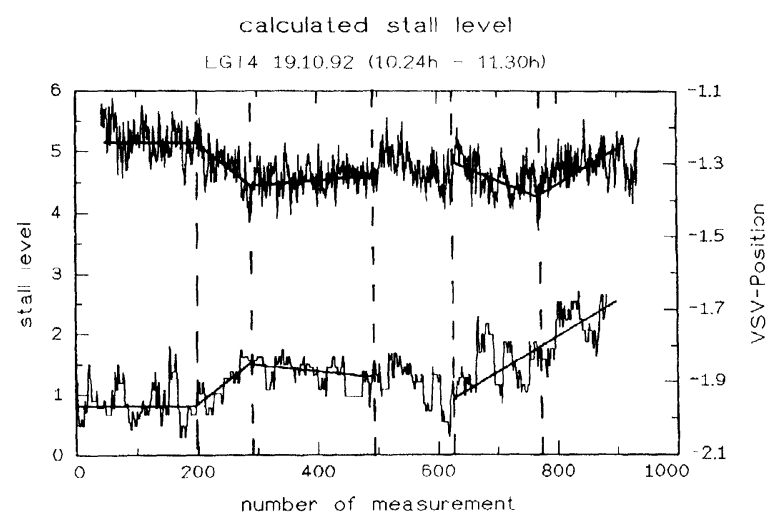

FIGURE 5 Comparison of the stall level with the setting of the VSVS. shows an example for the behavior of one of these indicators applied to the data of four test runs. The diagrams show the distribution of one chosen parameter for increasing aerodynamic load.

The computerized analysis of the data is carried out as a classification of the parameter features due to the different test conditions. This process cannot take into account all quantities which influence the behavior of the parameters. Therefore, it provides results which are not exactly reproducible. Neural nets are good instruments for the solution of such tasks. For the data analysis shown here a Kohonen-type net was used.

In a first phase the net was trained with the data of the first test run of the compressor. In the following this net was applied to the parameter sets of all tests. For the test runs \#1 and \#4 a good classification of the measuring points concerning the approximation to the stability limit could be observed. The test runs \#2 and \#3 were not analyzed correctly. The comparison between the boundary conditions of the tests show similar conditions in the 1 st and 2 nd and in the 3 rd and 4 th test run (see Table I). The main influence is obviously caused by the VSV angle.

In a second phase the neural net was additionally trained with the parameters of test run \#3. The following applications of this net to the parameter sets of all test runs demonstrated quite a better agreement concerning the 3 rd test. Only for the 2 nd test run of the compressor the increasing aerodynamic load could not be detected. Figure 7 demonstrates an result of those classifications with the neural net. The $5 \times 5$ dimensioned output layer with the distribution of the best answering neurons is shown here. The numbers inside the fields are the definitions of the aerodynamic load similar to the curves in Fig. 4.

The circles indicate an agreement in the different test runs. It becomes visible that for example in all tests the neuron \#5, 1 (5th column, 1st row) shows the best reaction to the conditions at normal operation of the compressor. For the test runs 1, 3 , and 4 the proximity to the stability limit of the compressor is recognized by neuron $\# 1,1$. 


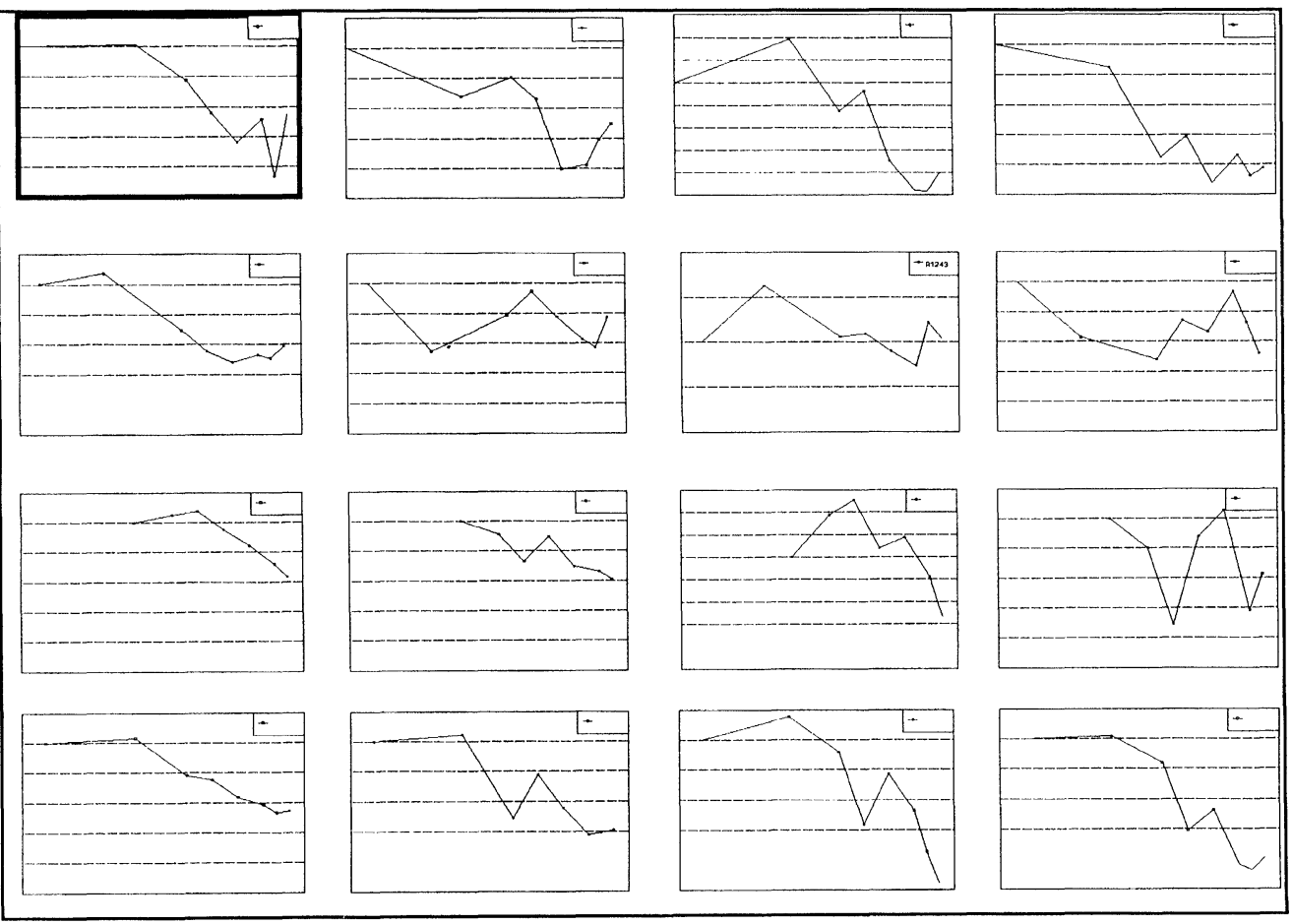

FIGURE 6 Distribution of the monitoring parameters for different test runs.

However, the nonsatisfactory results concerning the 2 nd test run become obvious. Therefore, now the parameter set for the analysis is expanded. In addition to the values calculated from the frequency spectra also the information from the real time signals and the RMS values must be taken into account in order to provide a reliable classification result.

\section{CONCLUSIONS}

The results from the measurements of three different compressors demonstrate the various possibilities of the detection of stall and surge in axial compressors. The measuring data provide a base for the definition of suitable parameters for the observation of aerodynamic load and the prediction of the stability limit. For a detailed analysis the observed effects must be transformed into a computer readable form.
Two examples of analyzing respective monitoring programs showed the different possibilities of measuring methods and the definition of monitoring parameters. A monitoring system developed for the industrial application uses a conservative method of data analysis. This real time system is running since 1991 at three 14-stage axial compressors and provides reliable results. The algorithms of this monitoring system were applied to the measuring data of the 17-stage compressor. Since the definition of the monitoring parameters is generally valid it was possible to calculate the monitoring values being in agreement with the operation conditions of the compressor.

Nevertheless, another analysis method for the measuring data was developed which contains another parameter definition. In order to speed up the monitoring time a classification based on neural nets was introduced. The first results of this system provided an ideal basis for the development of a new on-line monitoring system for multi stage 


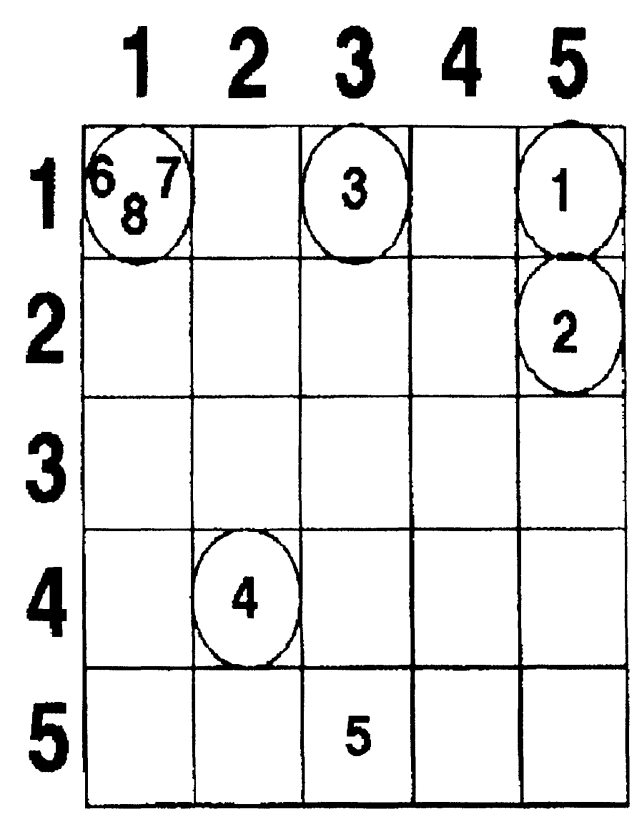

test run \#1

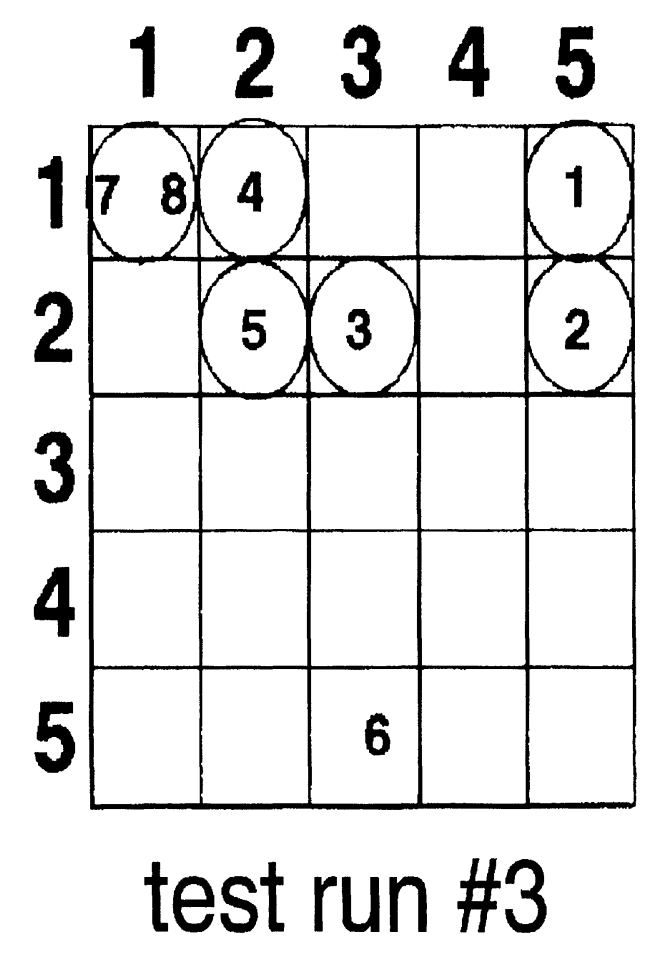

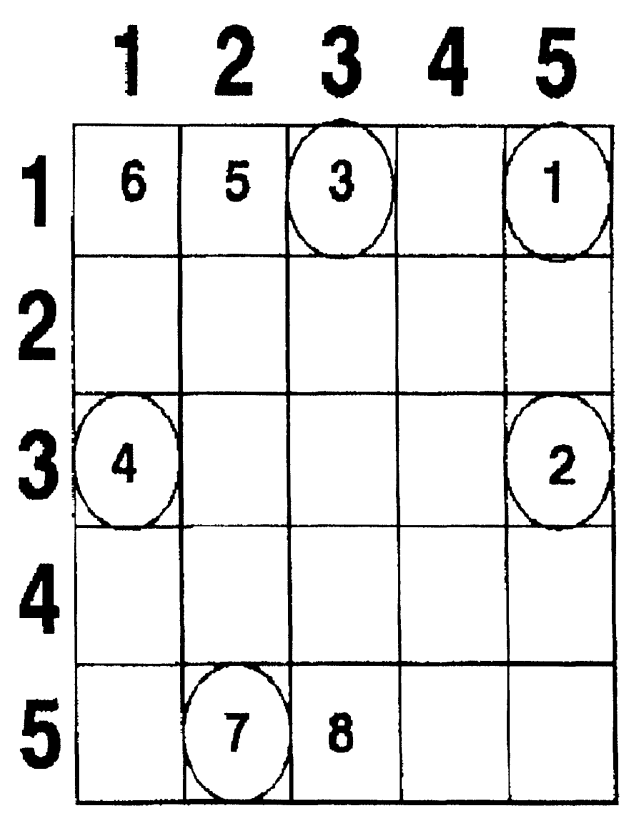

test run \#2

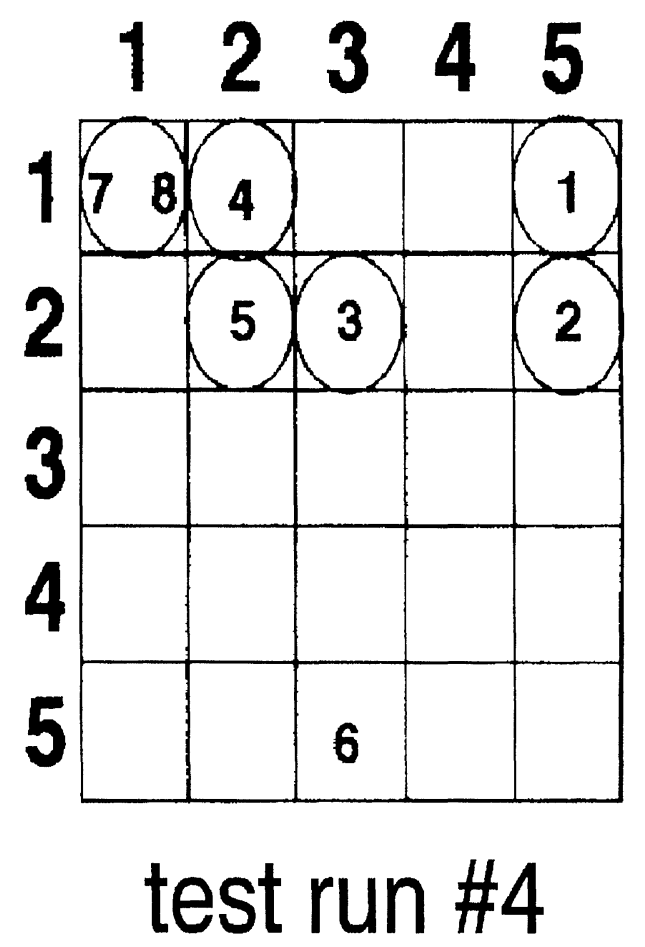

test run \#4

FIGURE 7 Analysis of the output layers of the neural net. 
TABLE II Comparison of the monitoring methods for both compressors

\begin{tabular}{ll}
\hline 14-stage compressor & \multicolumn{1}{c}{ 17-stage compressor } \\
\hline Full load operation & Part load operation \\
Measurements in the end stages & Measurements in the front stages \\
Sensor positions in the axial gaps & Sensor positions over the rotor \\
Analyzed phenomenon: blade wakes & Analyzed phenomenon: tip leakage flow \\
Parameter behavior: increase/decrease & Parameter behavior: continuous decrease \\
Monitoring of compressor load by an analyzing algorithm & Monitoring of compressor load by classification with neural nets \\
\hline
\end{tabular}

compressors. The main advantage is the possibility of applications in a wide operating range of the compressor. Table II gives a short comparison of the features of both monitoring methods.

As the results demonstrated both methods are able to provide a detailed information about the operating condition inside the compressor. The analysis with neural nets has to be expanded by additional parameters in order to increase the reliability. The next step must be the application of this method in an on-line system.

\section{References}

Garnier, V.H., Epstein, H. and Greitzer, E.M. (1990) Rotating waves as a stall inception indicator in axial compressors, ASME Paper No. 90-GT-156.
Gallus, H.E. and Hönen, H. (1986) Experimental investigation of airfoil- and endwall boundary layers in a subsonic compressor stage, ASME Paper No. 86-GT-143.

Hönen, H. and Gallus, H.E. (1995) Monitoring of aerodynamic load and detection of stall in multi stage axial compressors, $J$. of Turbomachinery, 117

Inoue, M., Motoo, K., Takahito, I. and Youichi, A. (1990) Detection of a rotating stall precursor in isolated axial flow compressor rotors, ASME Paper No. 90-GT-157.

Ludwig, G.R. and Nenni, J.P. (1979) A rotating stall control system for turbojet engines, J. Engineering for Power, 101.

Paduano, J., Epstein, A.H. and Greitzer, E.M. (1991) Active control of rotating stall in a low speed axial compressor, ASME Paper No. 91-GT-88.

Wang, H., Hennecke, D.K., König, A., Windirsch, P. and Glesner, M. (1993) An Approach to the stall monitoring in a single stage axial compressor, 29th Joint Propulsion Conference, Monterey, CA, AIAA-93-1872. 


\section{ait \\ ENERGY MATERIALS}

M A N E Y publishing

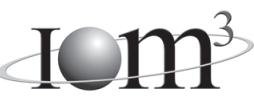

\section{Materials Science \& Engineering for Energy Systems}

Maney Publishing on behalf of the Institute of Materials, Minerals and Mining

The Institute of Materials, Minerals \& Mining

Economic and environmental factors are creating ever greater pressures for the efficient generation, transmission and use of energy. Materials developments are crucial to progress in all these areas: to innovation in design; to extending lifetime and maintenance intervals; and to successful operation in more demanding environments. Drawing together the broad community with interests in these areas, Energy Materials addresses materials needs in future energy generation, transmission, utilisation, conservation and storage. The journal covers thermal generation and gas turbines; renewable power (wind, wave, tidal, hydro, solar and geothermal); fuel cells (low and high temperature); materials issues relevant to biomass and biotechnology; nuclear power generation (fission and fusion); hydrogen generation and storage in the context of the 'hydrogen economy'; and the transmission and storage of the energy produced.

As well as publishing high-quality peer-reviewed research, Energy Materials promotes discussion of issues common to all sectors, through commissioned reviews and commentaries. The journal includes coverage of energy economics and policy, and broader social issues, since the political and legislative context influence research and investment decisions.

\section{CALL FOR PAPERS}

Contributions to the journal should be submitted online at http://ema.edmgr.com

To view the Notes for Contributors please visit: www.maney.co.uk/journals/notes/ema

Upon publication in 2006, this journal will be available via the Ingenta Connect journals service. To view free sample content online visit: www.ingentaconnect.com/content/maney

For further information please contact:

Maney Publishing UK

Tel: +44 (0)113 2497481 Fax: +44 (0)1132486983 Email: subscriptions@maney.co.uk

or

Maney Publishing North America

Tel (toll free): 8662975154 Fax: 6173546875 Email: maney@maneyusa.com

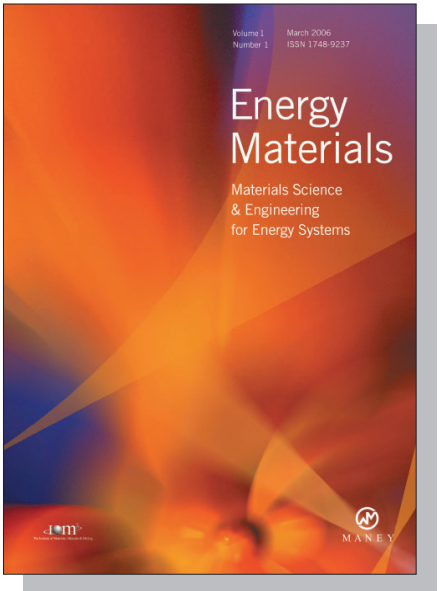

EDITORS

Dr Fujio Abe

NIMS, Japan

Dr John Hald, IPL-MPT, Technical University of Denmark, Denmark

Dr R Viswanathan, EPRI, USA

\section{SUBSCRIPTION INFORMATION}

Volume 1 (2006), 4 issues per year

Print ISSN: 1748-9237 Online ISSN: 1748-9245

Individual rate: $£ 76.00 / U S \$ 141.00$

Institutional rate: $£ 235.00 /$ US $\$ 435.00$

Online-only institutional rate: $£ 199.00 / U S \$ 367.00$

For special $\mathrm{IOM}^{3}$ member rates please email

subscriptions@maney.co.uk

\section{For further information or to subscribe online please visit www.maney.co.uk}



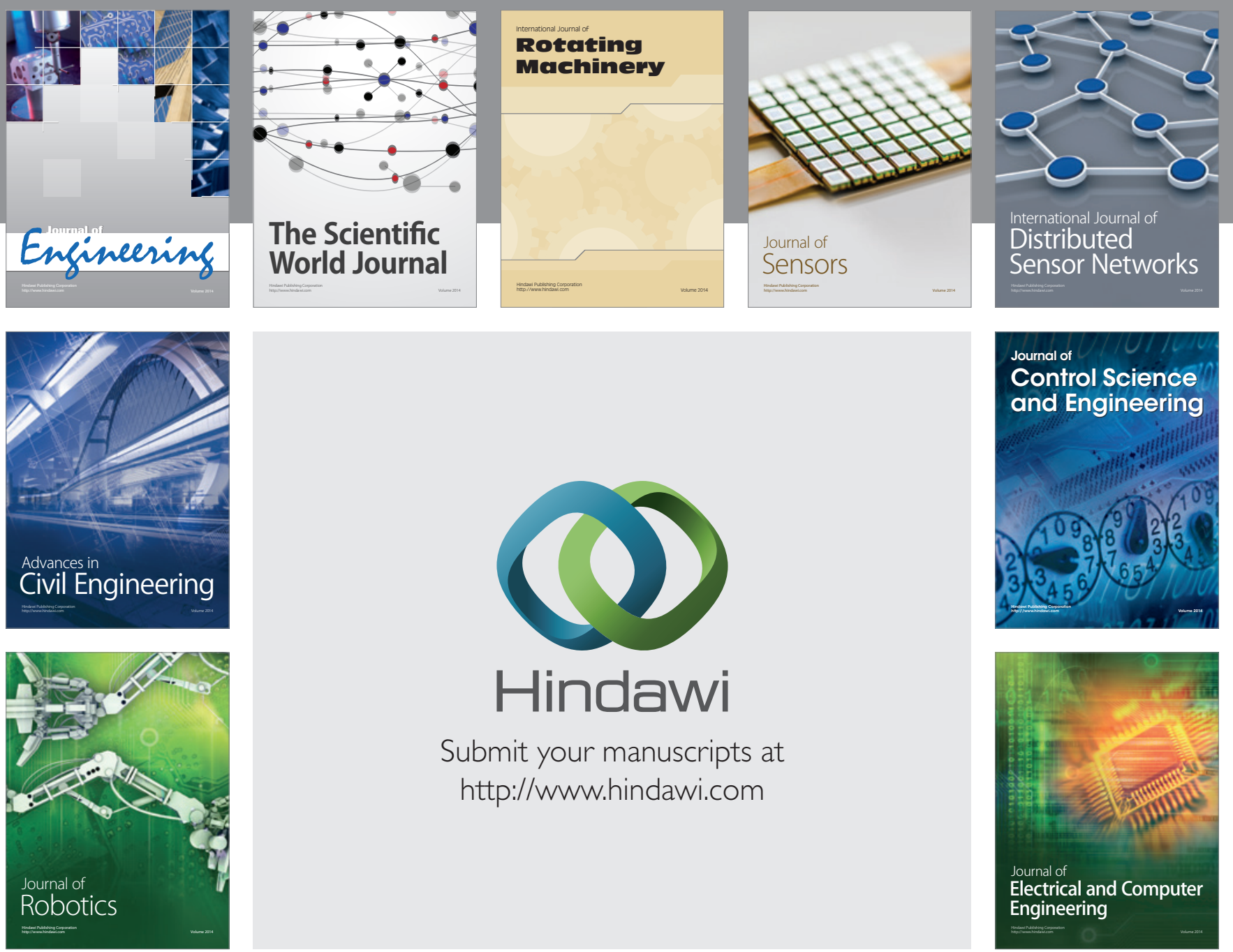

Submit your manuscripts at

http://www.hindawi.com
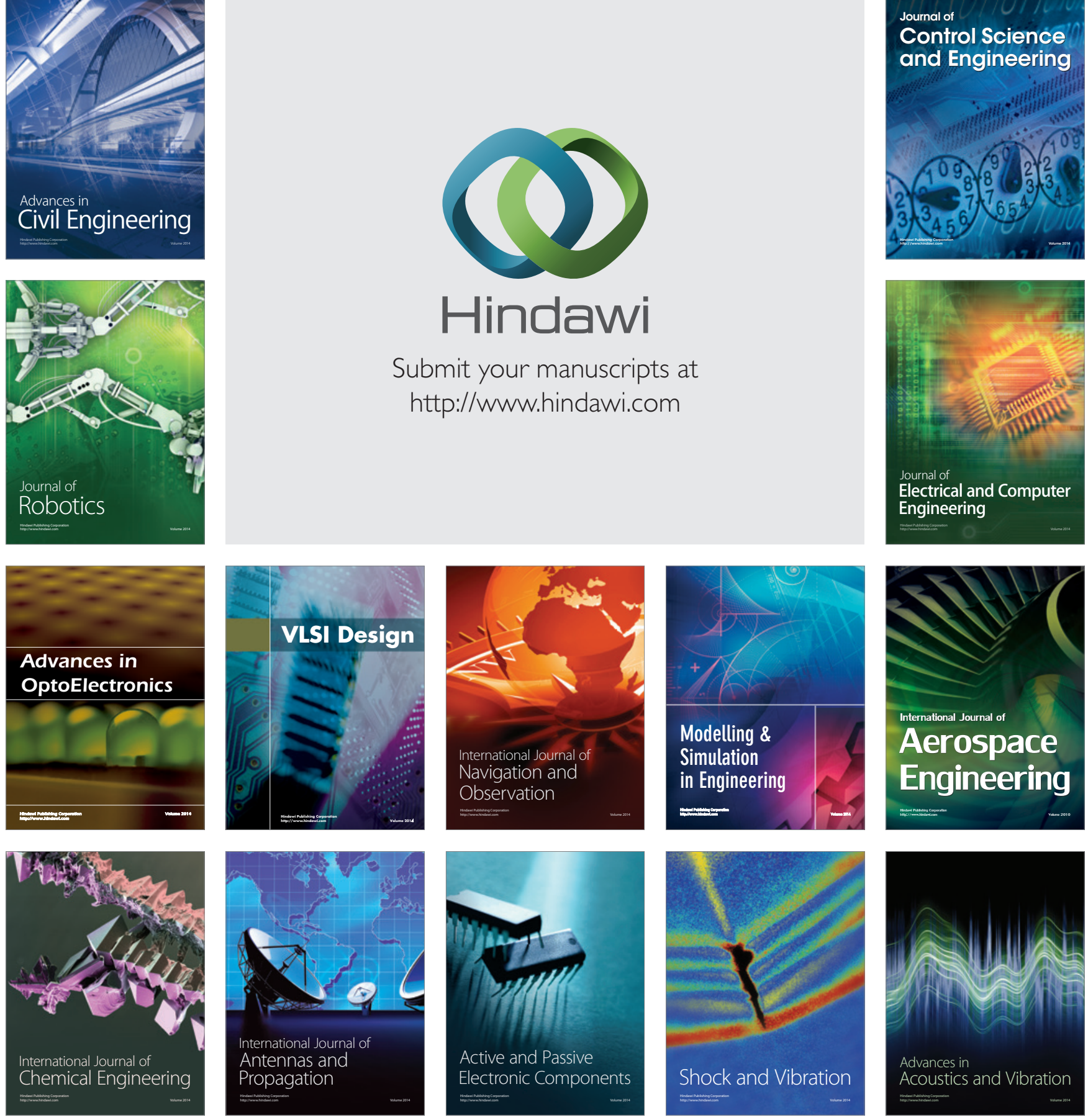